\title{
A traduçáo da comédia grega: As Nuvens
}

\author{
Andreza Caetano ${ }^{1}$
}

\begin{abstract}
Resumo: $O$ artigo trata da tradução de comédia e propõe que a traducão crie uma voz. teatral e não literária, mostrando as diferenças sintáticas e semânticas que podem surgir quando se considera antes a encenação que a literatura e a leitura. Não há razão para deixar de absorver a natureza da comédia grega e transformá-la naquilo que ela não é. Abordaremos também questões que nos pareceram polêmicas no processo de tradução, como a tradução do bumor e o embelezamento que o texto traduzido costuma sofrer, para mostrar as soluções por que optamos.
\end{abstract}

Palavras-chave: teatro grego; tradução; Aristófanes; As Nuvens; comédia.

A tradição tem alterado em muitas obras a real significação do texto grego, afastando-o do leitor e criando a imagem, que se perpetua, de que a cultura clássica é inacessível ou difícil. Se as traduções fossem mais claras, possivelmente mais pessoas conheceriam e admirariam textos antigos e não os entenderiam como leitura pedante, feita só quando obrigatória, nas escolas, por exemplo. Ainda que façamos algumas alterações, e obviamente as teríamos que fazer, pois as línguas possuem estrutura diferente, não deveríamos, como estudiosos e tradutores, impregnar as obras de termos desnecessários que não fazem mais que alongar ou protelar a transmissão da ideia proposta no original. A preocupação em popularizar o teatro clássico levou-nos de algum modo a interpretar o texto grego a partir da perspectiva cenográfica, e não somente literária. Encontramos belas traduções de comédia que, contudo, não são adequadas à representação nos palcos por apresentar sintaxe pesada e imprópria para a comédia. Por isso, nossa preocupação maior não é construir um texto pleno de beleza literária, mas sim pleno de diversão, enfim, um texto de comédia, um texto que cumpra em definitivo sua função.

1 CAETANO, A. S. A. M. andrezacaetano@yahoo.com.br 
Propomos criar um texto leve e deixar espaços em branco na mente de quem lê, espaços que deverão ser preenchidos pelos gestos, entonação de voz e postura do ator. Esse espaço ocupará a mente do diretor e ator da peça, assim como de um leitor, que poderá interagir com o texto e visualizar cenas como melhor the parecer. Para marcar tais espaços na tradução podem ser usadas reticências e até ausência de conexão sintática.

Não se pode adotar a mesma atitude para traduzir um poema lírico, um texto em prosa e uma peça teatral. Observar a função do texto, isto é, se é destinado à leitura ou ao audição ou à encenação, é de extrema importância para traduzi-lo. Susan Bassnet, em Problemas Especificos da Tradução Literária, (2003, p. 136) diz que

O tipo de reprodução da forma, do metro, do ritmo, do tom, do registro, etc. será determinado tanto pelo sistema de partida como pelo sistema de chegada e dependerá também da função da tradução, [... pois os] critérios que regem os modos de tradução têm sofrido variações consideráveis ao longo dos tempos e não há, certamente, nenhuma fórmula modelo para os tradutores seguirem.

O texto teatral deve demonstrar uma linguagem espontânea, oral, embora saibamos que primeiramente é escrito: trata-se de um texto escrito que pretende ser oral. Esta consciência é imprescindível no momento da tradução de uma peça, seja ela comédia, tragédia ou drama satírico. Como mencionou Lambert em Verso e Prosa na Época Romântica (1985, p. 121) “a oposição entre verso e prosa engendra mudanças na hierarquia dos valores literários e, paradoxalmente, o teatro é o primeiro a sofrer esta revisão de valores que atinge as convenções literárias". Sabemos que somente a partir do século XVII é que o teatro assume papel central nas polêmicas sobre experimentações literárias - mais que a poesia e a própria prosa - e que desde então o verso deixa de ser a única forma da escrita teatral, e que todas essas transformações afetaram também os tradutores, que se viram no dilema de escolher entre manter a forma tradicional do teatro e traduzir em versos ou mesclar verso e prosa, usando uma linguagem mais coloquial que busque misturar registros linguísticos. Surge deste dilema a separação entre "teatro para ser lido" e "teatro para ser encenado". (LAMBERT, 1985, pp. 127-129). Bassnet comenta que "parece que é mais fácil para o incauto tradutor de prosa considerar a forma e o conteúdo como instâncias separáveis" (BASSNET, 2003, p. 175); mas "se o tradutor se ativer apenas ao conteúdo específico da frase, o produto perderá a dimensão" (BASSNET, 2003, p. 182), o que prova "a necessidade de o tradutor considerar o texto narrativo como uma entidade estruturada, tendo sempre em conta as exigências estilísticas e sintáticas da língua de chegada" (BASSNET, 
2003, p. 185) e da língua de partida. É necessário considerar que “todo texto se compõe de uma série de sistemas concatenados, tendo cada um deles uma função determinável em relação ao texto inteiro, e a tarefa do tradutor é apreender estas funções" (BASSNET, 2003, p. 186) ${ }^{2}$. Deve-se descartar a noção de igualdade entre a língua de partida e a de chegada. "O tradutor deve, portanto, em primeiro lugar, determinar a função do sistema da língua de partida e procurar um sistema na língua de chegada que cumpra essa mesma função" (BASSNET, 2003, p. 189). Ainda assim, cremos conveniente esclarecer que paralelamente à polêmica da fidelidade ao texto - polêmica que perpassa a história da teoria da tradução -, entendemos que o pleno entendimento e a aproximação com autor, com sua época, com sua sociedade e cultura tornam desnecessárias quaisquer alterações ou embelezamentos a que o tradutor possa se sentir impelido. Traduzir uma obra teatral significa traduzir um conjunto que ultrapassa o texto para alcançar o corpo do ser humano e até sua capacidade de ver e imaginar.

Atualmente o texto dramático tem sido tratado mais como poesia, o que deturpa sua função originária. Desrespeitar tal função pode ser opção do tradutor, mas transformar a espontaneidade oral em algo cheio de formalidade, segundo a norma culta da língua de chegada, incluindo conectores onde não há, subordinando orações que eram coordenadas e tornando impecável o que surgira para ser falado, - mesmo tendo sido escrito em metro ${ }^{3}$-, é transgredir o próprio texto teatral. Manter essa formalidade só se justifica se for traço da personagem. Não ignoramos que a escrita é invenção humana e que, portanto, os textos dramáticos apresentavam traços da formalidade própria da escrita. Por isso, é necessário, em primeiro lugar, que o tradutor estabeleça a função que terá a tradução e observe a que público se destina. Deve-se ter em mente, como ressaltou Lefevere, em Traducción, Reescritura y la Manipulación del Canon Literario (1997, p. 126), que "ao tradutor se impõe a "poética da tradução" de sua época". Bassnett (2003, pp. 193196) afirma que, quando o tradutor de teatro assume o pré-requisito da representabilidade, deve agir diferentemente de um tradutor de outros tipos de textos, pois cabe-lhe entender e "partir do princípio" de que o texto teatral foi elaborado para

2 Nas páginas 183-185, Bassnett cita as seis regras gerais de Hilaire Belloc para o tradutor de textos narrativos: 1) o tradutor não deve arrancar palavra por palavra ou frase por frase, mas deve proceder sempre por blocos, traduzir por seções. 2) Deve-se traduzir expressão idiomática por expressão idiomática correspondente. 3) Deve-se traduzir intenção por intenção, tendo-se em mente que a intenção de uma frase em uma língua pode ser muito mais enfática que em outra. 4) $O$ tradutor deve estar atento aos falsos cognatos. 5) Deve-se "transmutar ousadamente". A essência da tradução é "a ressurreição de um objeto estranho num corpo nativo". 6) O tradutor não deve embelezar o texto original.

3 Sabe-se que na antiguidade a métrica também era utilizada para facilitar a memorização, e não somente por questões de estética na poesia. 
a encenação e, assim, apresenta características estruturais próprias que o tornam representável "aquém e além das orientações da encenação". O tradutor deve perceber tais características e traduzi-las para sua língua, ainda que isso implique "transformações significativas nos planos linguístico e estilístico". As observações do tradutor devem incluir, necessariamente, o ritmo inscrito na linguagem que determina o desempenho físico do ator. Parece-nos inconcebível, pois, que peças inteiras tenham sido traduzidas pensando-se somente no público leitor, ignorando a representabilidade em favor da literalidade e da fidelidade linguística. Ora, poderíamos sempre indagar o que é fidelidade linguística no texto teatral, uma vez que é imprescindível reconhecer expressões coloquiais, falsos cognatos, expressões idiomáticas e outros elementos semelhantes e verter por expressões coloquiais, falsos cognatos, expressões idiomáticas da língua de chegada que sejam equivalentes quanto ao sentido, ainda que ao pé da letra sejam diferentes.

Estamos aqui tratando mais especificamente da tradução do humor e assim cabe refazer a pergunta feita por Marta Rosas, no artigo "Por uma Teoria da Tradução do Humor" (2003, p. 133): “O que se deve, ou o que se pode fazer para que o humor funcione em outra língua?”. Devemos primeiro levar em conta o contexto histórico e cultural das cenas na língua de partida e tentar transpor o riso para a língua de chegada sem esquecer, como é óbvio, o contexto linguístico, pois "para abordar a prática da tradução, é inevitável adotar uma visão que reúna as mais diversas formas de investigação, tendo sempre como horizonte o tecido cultural das línguas" (ROSAS, 2003, p. 134). A autora, citando Raskin (ROSAS, 2003, p. 142), indica o modo próprio para transmitir com eficácia uma mensagem humorística e descreve os passos a seguir na construção lógica do humor, dentre os quais nos interessa ressaltar que a qualidade da "piada" está diretamente relacionada com o conhecimento que o receptor tem do universo da piada. Sendo assim, na tradução das peças gregas, por exemplo, resulta-nos mais difícil pensar a tradução sem que haja alterações profundas, uma vez que o universo grego é praticamente desconhecido da grande maioria da população brasileira. As trocas verbais que produzem humor são muito difíceis de traduzir na maioria das peças, pois implicam a cooperação do público com tudo o que é dito e feito pelos atores. Além disso, a crítica aos políticos e a outras personalidades, a divergência quanto a atitudes na sociedade, na maioria das vezes deixam de ser engraçadas porque o receptor desconhece as situações e pessoas apresentadas.

Analisemos uma das comédias de Aristófanes. Em As Nuvens, há o debate entre o Raciocínio Justo e o Raciocínio Injusto, personificados. O público não-especialista do século XXI não sabe que se trata de crítica à nova educação sofista na Atenas de 423 a.C. De qualquer forma, o problema da educação transpõe as 
barreiras do tempo e pode ser tema atual em qualquer época. No verso 889 ocorre o célebre aforismo: $\gamma \nu \tilde{\omega} \theta \mathrm{l} \sigma \varepsilon \alpha v \tau o ́ v$ - "conhece-te a ti mesmo" -, que pode não ser entendido por todos, mas vale a pena ser respeitado. Em resposta, o Raciocínio Injusto diz "Vá para onde precisas", um argumento considerado afeminado, mas não necessariamente homossexual, que quer dizer "Vá para o quinto dos infernos" ou outros bordões parecidos. Desejar rapazinhos era hábito normal para os gregos, especialmente para os mais antigos! Havia a concepção de que os homens aprendiam a amar com outros homens, para então, depois, se casar e constituir família. Quando o Raciocínio Justo se refere ao Injusto chamando-lhe afeminado, quer dizer que o outro só se fazia acompanhar de mulheres e, por isso, não desejaria os rapazes! Esse pensamento é contraditório com o que temos hoje de um homem que vive acompanhado de mulheres, que sai com muitas mulheres! Hoje, a imagem desse afeminado de Atenas seria a de um "garanhão". No verso 909, o Raciocínio Justo qualifica o Injusto como $\alpha \alpha \tau \alpha$ ú $\gamma \omega v$, termo que indica o temperamento libidinoso e o exagerado apetite sexual dos mais jovens. Neste caso, ele o acusa de depravação também por desejar mais as mulheres, já que a partir do verso 917, o Raciocínio Justo diz que, se todos seguirem os conselhos do Raciocínio Injusto, não procurarão mais pelos "rapazinhos" e todos os atenienses saberão que

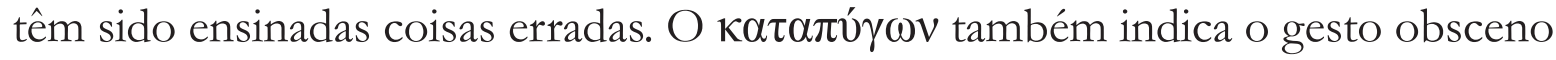
representado pelo dedo médio. Todos estes detalhes conferem ao texto original intensa ironia. Uma possível atitude do Raciocínio Justo fazendo o gesto obsceno provocaria o riso exatamente por não condizer com sua fala e seu comportamento. É o riso provocado pelo ridículo, tornando a situação mais espirituosa. De igual modo, quando o Raciocínio Injusto usa registro mais formal - discernindo reflexões desconhecidas! - fica claro que está sendo sarcástico, e a fuga do padrão habitual da personagem também torna a situação engraçada. Neste caso nos deparamos com uma quebra devida à troca verbal, e o estilo linguístico da personagem, que contrasta com seu perfil, demonstra este sarcasmo, pois é "aparentemente sincera e não provoca nenhum sentimento de contradição", mas estabelece um choque no seio da dinâmica interna do texto, como indica Marta Mateo, quando distingue recursos para traduzir humor no artigo "A tradução da Ironia", de 2010.

Esta dinâmica interna, segundo Benjamin La Farge (2004, p. 118), dirige a reação do leitor/expectador, que é engatilhada pela expressão e pelo gesto do ator, pelas palavras usadas ou pela combinação das três coisas. Há uma intenção geral no plano de toda comédia, que nos remete ao riso e cada ideia apresentada no scriptilumina e fortalece esta intenção. Consideramos importante que o tradutor esteja atento aos momentos nos quais estabelecerá as posturas das personagens, ora sarcástico, como acima citado, ora irônica, quando a mesma personagem diz "Tu acaba de falar rosas pra mim!" ou "me coroa com lírios". Nesta situação, 
temos duas realidades distintas apresentadas como verdadeiras (MATEO, 2010). O Raciocínio Injusto diz receber rosas - querendo dizer que recebe elogios, exaltações - quando sabe que o justo o está enxovalhando, tentando humilhá-lo. Ele diz algo - uma realidade - que não condiz com a realidade implicada no contexto. É preciso estar atento a todos os traços do próprio texto que demarquem os gatilhos do riso, entendendo que os sinais podem estar no contexto - o que envolve o conhecimento de mundo do autor, do tradutor e do expectador -, podem acompanhar o próprio texto - gestos -, ou ainda podem ser parte do texto em si (MATEO, 2010).

No verso 897, temos uma clara crítica à educação antiga (encontram-se, averiguam-se, reconhecem-se novas opiniões, novos conhecimentos, conhecimentos extraordinários, inesperados), que representa também um problema na

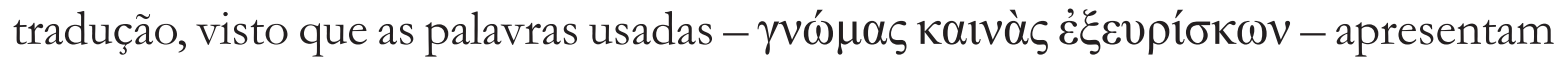
significados variados que podem alterar a nuance do que é dito, e no humor, o tom em que algo é dito é irrefutavelmente basilar.

Tentamos, e consideramos extremamente importante na tradução do teatro, deixar bem marcadas as características dos falantes. Neste caso, o Raciocínio Justo personificado representa a educação antiga e, ao que nos parece, mais erudita - já que se trata de uma crítica à nova educação -, enquanto o Raciocínio Injusto não passa de um jovem néscio que pode até ser capaz de usar bem as palavras para convencer o interlocutor, mas não tem sabedoria profunda. A fim de definir essa diferença linguística, cremos conveniente muitas vezes traduzir a ideia do que foi dito em grego pela ideia correspondente no português, como acontece no verso 898, quando o Raciocínio Injusto diz: "Mas eu te revirarei todo, constrangendo-te; pois, com efeito, digo não haver justiça!". Este registro estaria adequado para o Raciocínio Justo, mas para o Raciocínio Injusto, segundo os parâmetros que estabelecemos, soaria completamente fora de lugar, ou seja, consideramos que transmitir a ideia pode ser, em alguns momentos, mais eficaz que transmitir a letra, e por isso, preferimos "Mas eu vou te regaçar todo, te fazendo passar vergonha - de boa, falo que não existe justiça!". Acreditamos que, inclusive a diferença de registro de língua entre os dois personagens pode provocar o riso.

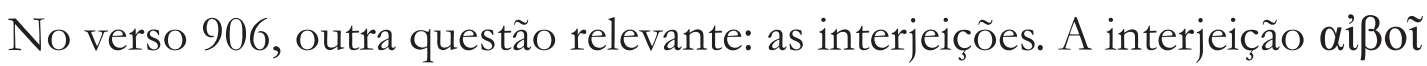
poderia significar simplesmente "ai", ou um "nossa!!!". Tentando ser coerentes com o todo, buscamos também alguma expressão das décadas passadas que soasse estranha a um jovem, tal como soa estranho aos adultos de hoje o modo de falar dos mais jovens. Assim, usamos "manjei".

No verso 914, o Raciocínio Injusto diz "e agora este mundo é meu", mostrando que é a época dele, a geração dele: colhemos e estudamos um vasto 
arsenal de gírias atuais para chegar à conclusão de que o melhor seria usar "é nóis na fita, mano!".

As escolhas que o tradutor tem diante de si são difićlimas, especialmente quando pensa exclusivamente na crítica, e a partir disso, opta por determinadas expressões e palavras, pensando menos na recepção popular que na acadêmica. Marta Rosas diz que a identificação e a cumplicidade do observador, ou seja, do público, é o que torna cômica a mensagem transmitida e a situação (2003, p. 138). Ela ainda acrescenta que (2003, p. 142)

No caso do texto humorístico, é preciso que o leitor/intérprete identifique o novo contrato que lhe está sendo proposto e aceite suas regras - que cumpra, portanto, a sua parte. Sua recompensa na relação espirituosa que estabelece com o emissor está tanto na apreensão de alusões e subentendidos que demandam o reconhecimento de padrões e o reconhecimento de contradições e desvios, quanto na verificação de sua própria capacidade de produzir associações, analogias e inferências, detectando o que está além da percepção do observado - ou seja, do alvo ou personagem cômico.

Do verso 908 ao 916 podemos perceber que os dois Raciocínios praticamente falam ao mesmo tempo. A percepção nos permite elaborar frases ligeiras que imprimam a ironia com que as personagens se tratam. Depois que o Raciocínio Justo pede uma bacia - para vomitar -, pois está enjoado com o comentário do Raciocínio Injusto, ele é chamado de nojento - no sentido também da soberbia - e os dois parecem discutir. Estes poucos versos seguem o ritmo de um pingue-pongue, no qual "a economia dos termos linguísticos é diretamente proporcional à produtividade do enunciado" (ROSAS, 2003, p. 143).

Vejamos a passagem ${ }^{4}$ :

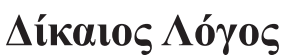

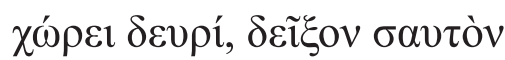

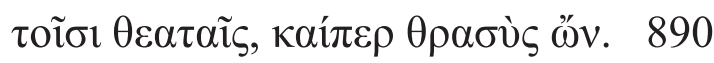

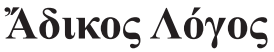



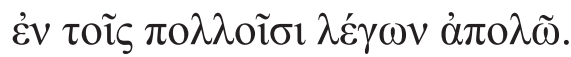

\section{Raciocínio Justo}

Corre aqui! Se és corajoso, mostra-te a ti mesmo para os que te vêem!

\section{Raciocínio Injusto}

Vai pro quinto dos inferno! Muito melhor é eu te destruir falando no meio da galera!

4 O texto grego foi retirado da página eletrônica do Perseus.

http://www.perseus.tufts.edu/hopper/text?doc=Perseus:text:1999.01.0027 


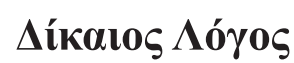

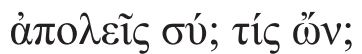

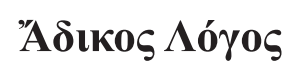

$\lambda$ ófos.

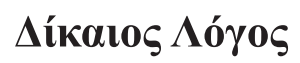

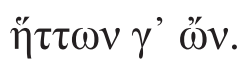

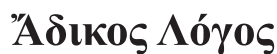

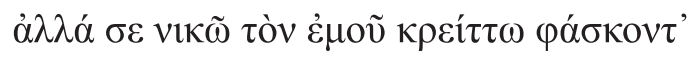
Eivval.

\section{\íkalos $\Lambda o ́ \gamma o s$}

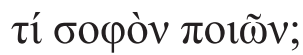

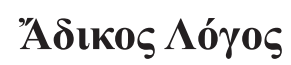

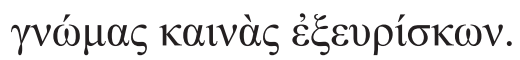

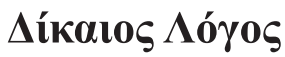

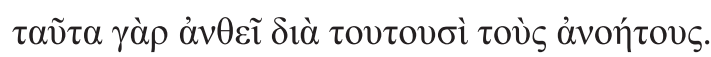

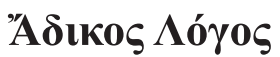

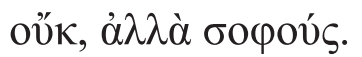

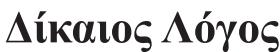

$\dot{\alpha} \pi \mathrm{\alpha} \lambda \tilde{\omega} \sigma \varepsilon \kappa \alpha \kappa \tilde{\omega} \zeta$.

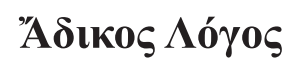

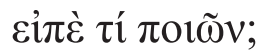

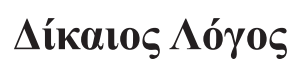





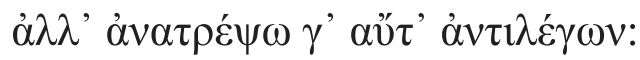

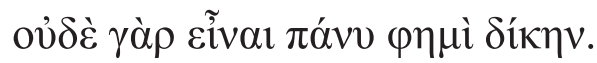

Raciocínio Justo

Tu? Destruirás? Sendo quem?

\section{Raciocínio Injusto}

Palavra.

\section{Raciocínio Justo}

Mas... e sendo inferior?!

\section{Raciocínio Injusto}

Mas vou te vencer! Tu que diz que é mais forte que eu!

\section{Raciocínio Justo}

895 Fazendo o quê de sábio?

\section{Raciocínio Injusto}

Discernindo reflexões desconhecidas!!

\section{Raciocínio Justo}

Pois tais coisas brotam no meio dos tolos!

\section{Raciocínio Injusto}

Não para os espertos!

\section{Raciocínio Justo}

Desgraçadamente destruir-te-ei!

\section{Raciocínio Injusto}

$900 \quad$ Fala aí! Fazendo o quê?

\section{Raciocínio Justo}

Dizendo coisas justas!

\section{Raciocínio Injusto}

Mas eu vou te regaçar todo, te fazendo passar vergonha! De boa, falo que não existe justiça! 


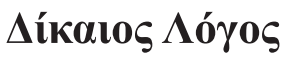

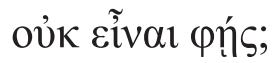

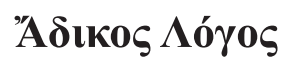

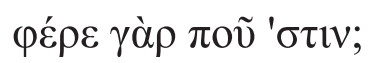

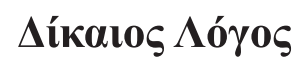

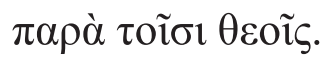

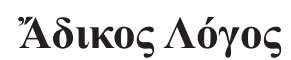

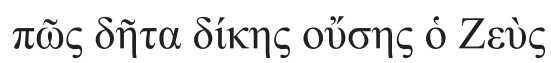

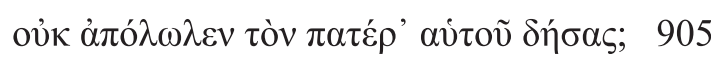

$\Delta$ Líkalos $\Lambda o ́ \gamma o \varsigma$

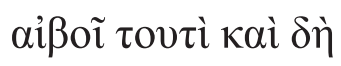

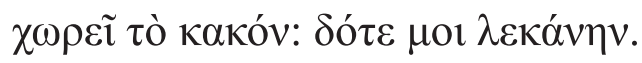

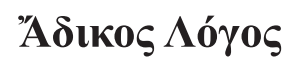

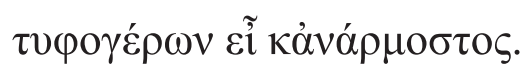

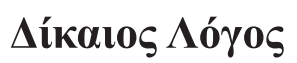

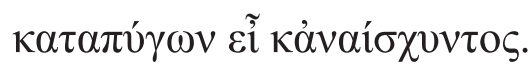

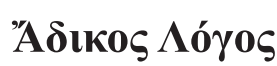

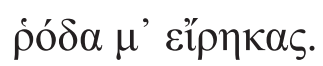

$\Delta$ úkalos $\Lambda$ ó

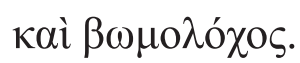

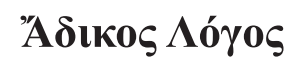

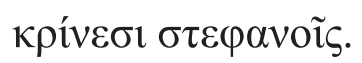

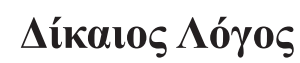

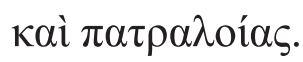

\section{Raciocínio Justo}

Dizes não haver?

\section{Raciocínio Injusto}

Então vamos ver! Onde está?

\section{Raciocínio Justo}

Junto dos deuses!

\section{Raciocínio Injusto}

Se existe justiça, como é que Zeus não morreu, depois que acorrentou o pai dele?

\section{Raciocínio Justo}

Manjei! Então é isso?

O mal avança! Dá-me uma bacia!

\section{Raciocínio Injusto}

Tu é um velho nojento e pré-histórico!

\section{Raciocínio Justo}

Tu és um libidinoso e sem vergonha!

\section{Raciocínio Injusto}

910 Tu acaba de me elogiar!

\section{Raciocínio Justo}

E fanfarrão!

Raciocínio Injusto

Tu me engrandece!

\section{Raciocínio Justo}

E parricida! 


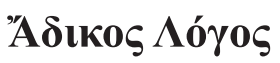

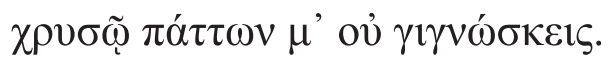

\section{$\Delta$ ú́каlos $\Lambda$ ó $\mathbf{0 s}$}

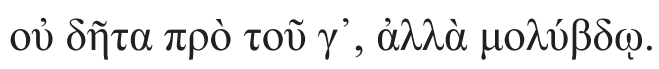

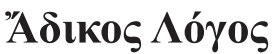

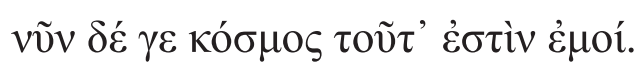

$\Delta$ \íkalos $\Lambda$ ó

$\theta \rho \alpha \sigma u ̀ \varsigma ~ \varepsilon i ̃ ~ \pi o \lambda \lambda ० \tilde{.}$

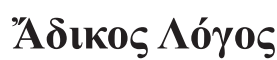

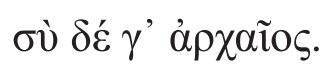

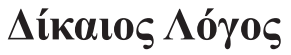

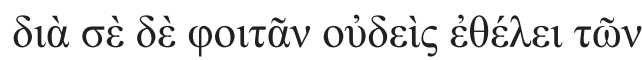

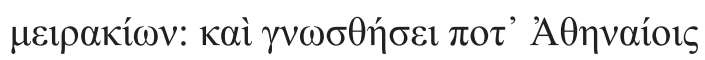

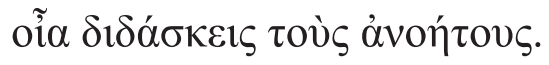

\section{Raciocínio Injusto}

Me louva! Tu não me conhece!

\section{Raciocínio Justo}

Certamente não! Se houvesse outro governo...

\section{Raciocínio Injusto}

É nóis na fita, mano!

\section{Raciocínio Justo}

915 És muito impetuoso!

Obviamente, não pretendemos exaurir a discussão sobre as possibilidades de traduzir uma peça teatral, e aqui viemos abordando um pequeno trecho de uma grande comédia. Cada uma apresenta um foco principal, a alma que serve de sustentação para tudo que é acrescido em torno. Em As Nuvens, trata-se de educação.

Buscamos, enfim, utilizando-nos das palavras de Rômulo Monte Alto (2005, p. 108), uma tradução na qual "a escrita transculturadora se orienta na direção de uma síntese que pacifique os elementos contrários em seu interior", na qual tais "elementos se organizem em torno de novas e desconhecidas pautas" sem "obstruir o sentido final, que antes atendia unicamente ao olhar criativo do autor".

\section{Referências}

BASSNETT, Susan. "Problemas Específicos da Tradução Literária". In: Estudos da Tradução, tradução de Sônia Terezinha Gehring, Letícia Vasconcelos Abreu e Paula Azambuja Rossato Antinolfi. Lisboa: Fundação Calouste Gulbenkian, 2003. pp. 128-174.

LA FARGE, Benjamin. Philosophy and Literature. Project Muse. Vol. 28, n. 1, abril 2004. pp. 118-136. 
LAMBERT, José. "Verso e Prosa na Época Romântica, ou a Hierarquia dos Gêneros nas Letras Francesas", tradução de Claudia Borges de Faveri. In: COSTA, Walter Carlos; GUERINI, Andréia; TORRES, Marie-Hélène Catherine (org.). Literatura e Traducão. Textos Selecionados de José Lambert. Rio de Janeiro: 7 Letras, 2011. pp. 119-135.

LEFEVERE, André. "La Traducción: el Lenguaje". In: Traducción, Reescrituray la Manipulación del Canon Literario, tradução de María Carmen África Vidal e Román Álvarez. Ediciones Colegio de España, 1997. pp. 125-138.

MATEO, Marta. "A Tradução da Ironia". In: Cadernos de Tradução, vol. 1, n. 25, 2010, Florianópolis. pp. 197-208.

MONTE ALTO, Romulo. "Os Territórios Intocados e os Espaços Vazios". In: A Literatura nas Fronteiras do Imaginário Latino-Americano. Tese de doutorado para obtenção do título de doutor em estudos literários, orientada por Eneida Maria de Souza. Belo Horizonte: Universidade Federal de Minas Gerais, 2005, inédita.

ROSAS, Marta. "Por uma Teoria da Tradução do Humor". In: DELTA - Documentação de Estudos em Linguiistica Teórica e Aplicada, n. 19 Especial, 2003. pp. 133-161. 